\title{
DECAY OF DELAYED LIGHT WITH THE DIATOM PHAEODACTYLUM TRICORNUTUM
}

\section{J.C. GOEDHEER and J. SWART}

Biophysics Research Group, Institute of Physics, Utrecht University, Utrecht (The Netherlands)

(Received January 13th, 1975)

(Revision received March 14th, 1975)

\section{SUMMARY}

Intact cells of the diatom Phaeodactylum tricornutum do not show a smooth afterglow decay curve. After a sharp decline (0-150 msec), a maximum may occur after $4 \mathrm{sec}$ at $17^{\circ}$ or after $22 \mathrm{sec}$ at $2^{\circ}$. This maximum is present after excitation with far red light of low intensity, which is absorbed primarily by photosystem I. It appears to be structure-bound: cell disintegration causes its disappearance, while the $150 \mathrm{msec}$ afterglow component is much less affected. The maximum also disappears after addition of 3-( $3^{\prime} 4^{\prime}$-dichlorophenyl)-1,1dimethylurea (DCMU) or ammonium chloride, but it remains unaffected by addition of phenazinemethosulphate (PMS) or pyocyanin. Addition of DCMU results in a strong increase in the $150 \mathrm{msec}$ afterglow when the cells are excited with far red light.

The experiments suggest that a diffusion-limited energy transfer mechanism, depending on the physiological state of the cell, is responsible for the maximum.

\section{INTRODUCTION}

Irradiated photosynthetic unicellular organisms or leaves emit an afterglow during a time ranging from several nsec to minutes after the end of illumination [1-3]. In the "long term" delayed light (assumed here to range from 200 msec to several minutes), a maximum in the decay curve is sometimes observed with intact cells or leaves [4-7]. This maximum was found to occur only after illumination with far red light. The experimental results diverge with respect to the time of its occurrence: it ranged from a few seconds [4] to a minute or more [7]. As also the intensity of incident light was different in the various experiments, maxima showing up at various moments during afterglow decay may be due to more than one mechanism. Addition of some artificial cofactors for photophosphorylation resulted in an increase in the "long term" afterglow and a shift of the maximum towards shorter times $[6,7]$. Abbreviations: DCMU, 3-(3'4'-dichlorophenyl)-1,1-dimethylurea; PMS, phenazinemethosulphate. 
From the very low concentration of the PMS needed to affect the "long wave" afterglow, Bjorn suggested that an "afterglow unit" the size of a thylakoid is present in the cell.

With isolated preilluminated spinach chloroplasts or chloroplast fragments the emission of a "light flash" could be brought about by the creation of an artificial proton gradient across the thylakoids by an acid-base transition $[8,9]$. This procedure can lead to phosphorylation. Also salt addition may stimulate luminescence with illuminated isolated chloroplasts $[10,11]$. Barber and Kraan [10] concluded from the maximum possible electrical gradient in their experiments that both $\mathrm{pH}$ and salt-induced luminescence should be independent of photophosphorylation.

With intact cells, however, the luminescence increase may be due to a different or a more complex mechanism, as suggested by the prolonged time elapsing between illumination and afterglow increase. In the present study the conditions for occurrence of the afterglow increase with Phaeodactylum are studied.

\section{METHODS}

Phaeodactylum was grown in diffuse daylight at $17^{\circ}$ in artificial seawater enriched with sodium silicate. These diatoms grow slowly but steadily over a period of several months, and their photosynthetic capacity, as measured with the oxygen polarograph, changes little. The percentage of long wave chlorophyll $a$, characteristic for fluorescence and absorption spectra of this organism, increases gradually during growth $[12,13]$.

Afterglow was measured with a circulating flow system. A cooling device enabled measurements to $-4^{\circ}$. The average time between illumination and measurement was $0.15 \mathrm{sec}$. Decay before $0.20 \mathrm{sec}$ is considered here to represent "fast" afterglow. Corrections were applied for the change in circulating velocity with changes in temperature. Illumination occurred with light isolated from a $150 \mathrm{~W}-24 \mathrm{~V}$ halogen lamp with a Bausch and Lomb grating monochromator $(500 \mathrm{~mm})$, with slit width between 1 and $2 \mathrm{~mm}$, depending on the intensity needed. Intensities exceeding $1 \mathrm{~W} \mathrm{~m}^{-2}$ were obtained with a slide projector and interference filters. The volume of the illuminated circuit was about 3 times that of the dark circuit. The average time needed by a cell to circulate the whole system was about $8 \mathrm{sec}$.

\section{RESULTS}

\section{Temperature}

The curves of afterglow decay $(0.15 \mathrm{sec} \leqslant t \leqslant 1 \mathrm{~min})$ emitted by a 2 month-old culture of Phaeodactylum suspended in or diluted with natural seawater and resulting from a 2-min illumination with light of $685 \mathrm{~nm}$ $\left(\sim 0.5 \mathrm{~W} \mathrm{~m}^{-2}\right)$ are given in Fig. 1 for various temperatures of the suspension. At temperatures below $20^{\circ}$ a pronounced maximum in the decay curve is 
observed. At $17^{\circ}$ it occurs at about $4 \mathrm{sec}$ after the end of illumination, while it is shifted towards longer times (12 sec at $7^{\circ}$ and $22 \mathrm{sec}$ at $\left.2^{\circ}\right)$ when the suspension is cooled. At temperatures above $20^{\circ}$ the maximum is observed as a shoulder in the decay curve of the "fast" luminescence component. The influence of temperature is reversible. At very low temperature $\left(-4^{\circ}\right)$ the maximum is low as compared to the "fast" afterglow. With other organisms (the green alga Chlorella vulgaris, the blue-green alga Synechococcus cedrorum and the red alga Porphyridium cruentum) the maximum can be measured but disappears when the cells are cooled below $7^{\circ}$, and reappears after warming.

\section{Wavelengths of excitation}

Fig.2 shows that no maximum in the afterglow decay curve is found upon preillumination in green light $(545 \mathrm{~nm})$, which is mainly absorbed by the carotenoid fucoxanthin, an accessory pigment of photosystem II. In this figure also the induction curves of afterglow, measured with light of 685 or $545 \mathrm{~nm}$ "on", are given. The shape of these curves depends on the wavelength of exciting light, as well as on light intensity and temperature. It is reproducible only if light of the desired wavelength is preceded by at least 1 min $545 \mathrm{~nm}$ light followed by 2 min dark adaptation.

From the afterglow values at the maximum in the decay curve a tentative

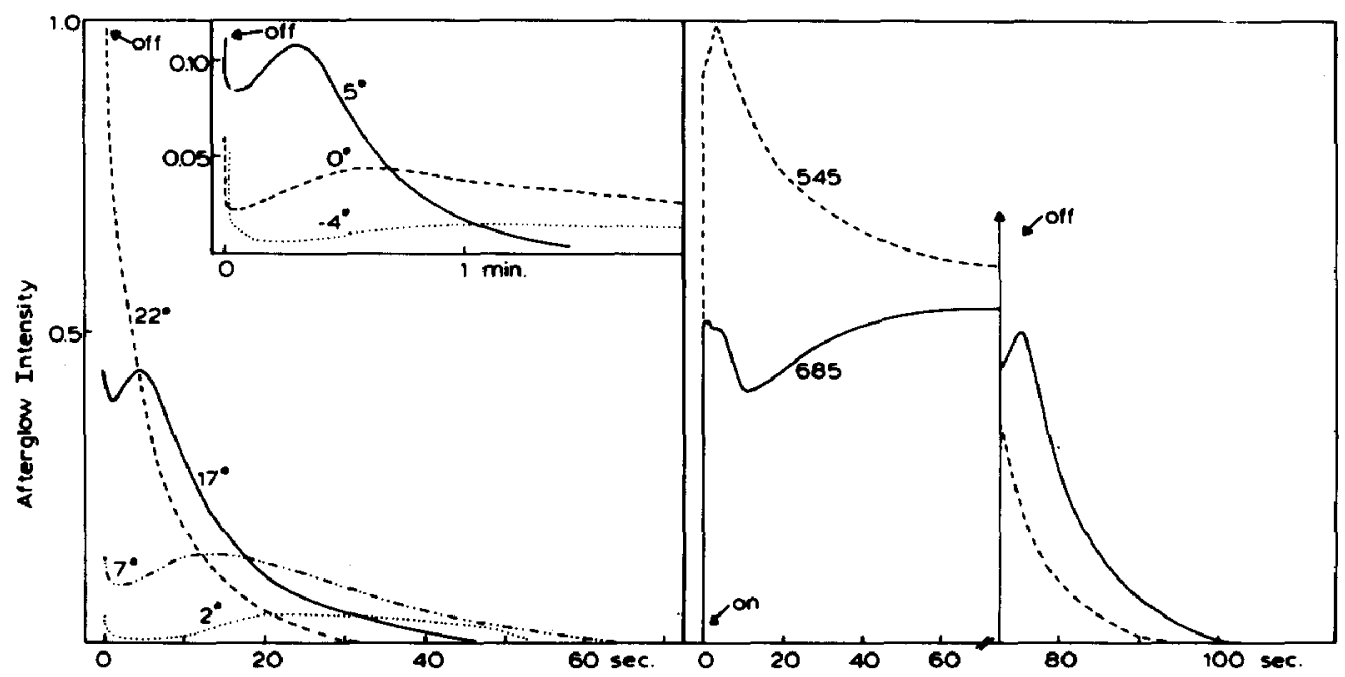

Fig.1. Afterglow decay curves of Phaeodactylum cells, resulting from a 2-min illumination with $685 \mathrm{~nm}$ light $\left(0.5 \mathrm{~W} \mathrm{~m}^{-2}\right)$ isolated with a monochromator ( $2 \mathrm{~mm}$ slit width), and measured at various temperatures. The insert gives the enlarged curves at some low tem'peratures.

Fig. 2. Afterglow induction (with light "on") and decay curves (with light "off") resulting from a 1-min illumination with $685(-)$ and $545(--) \mathrm{nm}$ light $\left(0.5 \mathrm{~W} \mathrm{~m}^{-2}\right)$ and measured at $13^{\circ}$. 


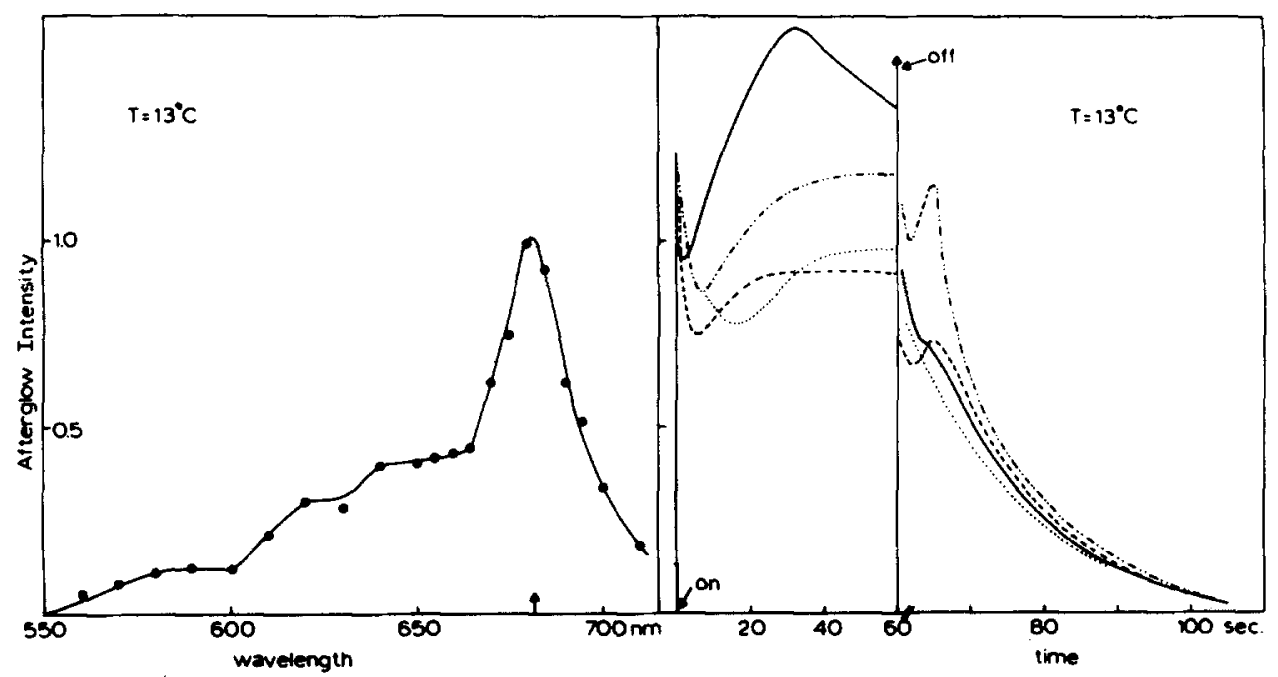

Fig. 3. Tentative action spectra of the contribution of the maximum to the afterglow decay curve of Phaeodactylum.

Fig.4. Induction and decay curves of afterglow different light intensities $\left(-, 5.5 \mathrm{~W} \mathrm{~m}^{-2}\right.$; ,$--- 4 \mathrm{~W} \mathrm{~m}^{-2} ;-\cdots-, 0.5 \mathrm{~W} \mathrm{~m}^{-2}, \cdots, 0.06 \mathrm{~W} \mathrm{~m}^{-2}$ ) resulting from $680 \mathrm{~nm}$ light (interference filter, $\lambda_{1 / 2}=11 \mathrm{~nm}$ ). Between $2 \mathrm{~W} \mathrm{~m}^{-2}$ and $0.2 \mathrm{~W} \mathrm{~m}^{-2}$ the curves are similar.

action spectrum of its occurrence can be derived (Fig.3). As no maximum is observed with green incident light, it is assumed that this light does not participate in reactions giving rise to the maximum. Therefore, the afterglow after $4 \mathrm{sec}$ resulting from illumination with light of $545 \mathrm{~nm}$, is subtracted from that at other wavelengths.

\section{Wavelength of emission}

Insertion of interference filters (maximum transmission at 680,695 and $714 \mathrm{~nm}$ ) between the detection cuvette and photomultiplier did not affect the shape of the decay curves. This indicates that the light emitted during: the whole time of afterglow had, probably, the same spectral distribution.

\section{Light intensity}

The influence of the intensity of the exciting light on the shape of the decay curves is given in Fig.4, when afterglow is excited with far red light. At intensities above $5.5 \mathrm{~W} \mathrm{~m}^{-2}$ the maximum in the decay curve disappears abruptly, while the $0.15 \mathrm{sec}$ component increases sharply. In a wide range of intensities little change is seen in the afterglow decay, whereas at low intensities $\left(<0.1 \mathrm{~W} \mathrm{~m}^{-2}\right)$ the maximum disappears.

\section{Illumination periods}

The maximum in the decay curve is not observed after short periods of 
illumination. After $4 \mathrm{sec}$ excitation with $685 \mathrm{~nm}$ light of $0.5 \mathrm{~W} \mathrm{~m}^{-2}$ at $15^{\circ}$ only a "fast" component is measured. After $16 \mathrm{sec}$ of illumination with this light the maximum in the decay curve is at its full intensity. No correlation between the sharp induction peak measurable during illumination and the maximum in the decay curve, was found.

\section{Cell structure and growth conditions}

After grinding, French press treatment, ultrasonic vibration or "osmotic shock" treatment of the cells no maximum in the decay curve could be measured. Fig. 5 shows the effect of "osmotic shock" treatment on a 6-weekold Phaeodactylum culture. Steady afterglow value at least with 545 and $685 \mathrm{~nm}$ excitation with illumination "on" are decreased. The maximum in the decay curve with illumination "off" disappears and the decay is similar for all wavelengths.

In younger cultures of Phaeodactylum ( $2-4$ weeks) the maximum is generally less pronounced than in older ones ( $1-6$ months). No further maxima at later stages in the decay curve were detected with cultures of different age grown under different light conditions, and measured at different light intensities and temperatures.

\section{Inhibitors, uncouplers and cofactors}

To obtain information about a possible influence of uncouplers of photophosphorylation, ammonium chloride was added. This treatment resulted in an $80 \%$ disappearance of the maximum in the afterglow decay curve at an ammonium chloride concentration of $10^{-2} \mathrm{M}$, while at $10^{-3} \mathrm{M}$ the shape of the decay curve was not affected, Ammonium chloride $\left(10^{-2} M\right)$ increases afterglow, when light is on, by $30 \%$. Potassium chloride $\left(10^{-2} M\right)$ did not have any effect on the shape or intensity of afterglow curves.

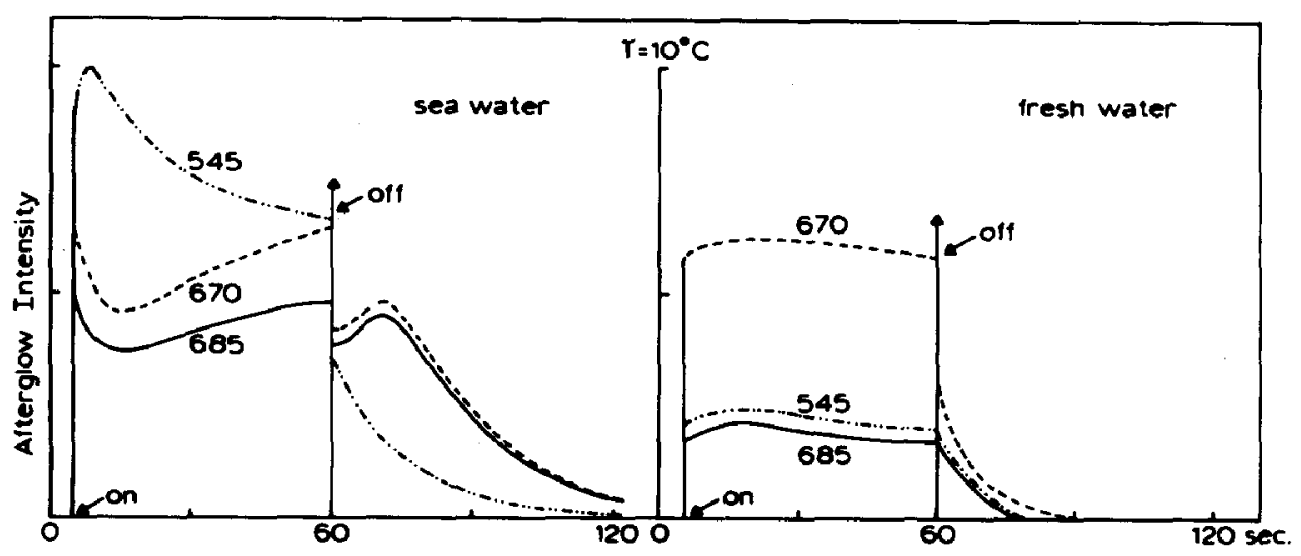

Fig.5. Decay and induction curves of Phaeodactylum diluted 15 times with seawater (left) or $0.02 M$ tris buffer pH 7.6 (right) and resulting from illumination at 685,670 and $545 \mathrm{~nm}$ (0.5 $\mathrm{W} \mathrm{m}^{-2}$ (right). 
Addition of the artificial cofactor for photophosphorylation PMS or pyocyanin $\left(10^{-7}\right.$ to $\left.10^{-4} M\right)$ did not have any effect on the afterglow curves in Phaeodactylum. A pronounced effect on the afterglow resulted from the addition of the photosynthetic inhibitor DCMU $\left(10^{-7}\right.$ to $\left.10^{-5} M\right)$. The afterglow intensity measured during $685 \mathrm{~nm}$ illumination increased about 5-fold, while the "long term" afterglow decreased and no maxima remained. The shape of the decay curves with $685 \mathrm{~nm}$ and with $545 \mathrm{~nm}$ now are similar and strongly resemble those obtained with disintegrated cells.

\section{DISCUSSION}

Light absorbed at $545 \mathrm{~nm}$ by the carotenoid fucoxanthin is transferred with high efficiency to chlorophyll of photosystem II, while at this wavelength, absorption by photosystem I pigments (long wave chlorophyll $a$ and $\beta$-carotene) is very low [14]. At $685 \mathrm{~nm}$, however, the absorption bands of chlorophyll $a$ from photosystem I and II overlap. As a result, less energy will be available for back reactions leading to light emission, resulting in a low yield of the $150 \mathrm{msec}$ component at this wavelength $[15,16]$. The experiments show that with intact cells, this "quenching" of the "fast" afterglow is abolished by addition of DCMU. After this treatment the ratio of afterglow excited with $685 \mathrm{~nm}$ light to that excited with $545 \mathrm{~nm}$ one is increased markedly and is similar to that observed with disintegrated cells. The "long term" emission, however, decreases strongly due to DCMU addition, while it also disappears due to structural changes, which leave the "fast" emission relatively unaffected. Several mechanisms seem possible to account for the increase in afterglow 4 to $60 \mathrm{sec}$ after illumination. The maximum could either be caused by an increase in fluorescence yield of the excited chloro phyll molecules, or by an increase in energy flow to photosynthetic intermediates, resulting in a larger number of excited chlorophyll molecules.

The afterglow value at the time of the maximum due to far red irradiation entirely to increase is about ten times higher than that due to irradiation with green light. It seems unlikely that the fluorescence yield also varies with this value, although the possibility of a change in fluorescence yield cannot be neglected.

An increase in energy flow towards intermediates remaining after illumination with system II light by products resulting from system I illumination seems more plausible. In view of the low intensities of exciting light needed to produce the maximum, the high temperature coefficient of the time of occurrence of the maximum ( $4 \mathrm{sec}$ at $17^{\circ}$ and $22 \mathrm{sec}$ at $2^{\circ}$ ) and its dependence on the structure of the cell, a diffusion-limited process seems compatible with the results reported here.

Whether this process is coupled with the $\mathrm{pH}$ and salt-induced afterglow increase observed with isolated chloroplasts and assumed to be caused by stimulation of an electrical gradient over the thylakoids $[15,16]$ remains to be investigated. 
The experiments show that with intact cells afterglow decay is markedly dependent upon physiological and environmental conditions. Hence determination of this parameter, especially when measured in combination with photosynthetic activity, can give valuable information about in vivo properties.

\section{REFERENCES}

1 B.L. Strehler and W. Arnold, J. Gen. Physiol., 34 (1951) 809.

2 W.F. Bertsch, J.R. Azzi and J.B. Davidson, Biochim. Biophys. Acta, 143 (1967) 129.

3 A. Haug, D.D. Jaquet and H.C. Beall, Biochim. Biophys. Acta, 283 (1972) 92.

4 W.F. Bertsch and J.R. Azzi, Biochim. Biophys. Acta, 94 (1965) 15.

5 A.B. Rubin, A.S. Fokht and P.S. Venediktov, Biofizika, 11 (1966) 341.

6 A.B. Rubin and P.S. Venediktov, Fiziol. Rast., 15 (1967) 34.

7 L.O. Bjön, Photochem. Photobiol., 13 (1971) 5.

8 B.C. Mayne and R.K. Clayton, Proc. Natl. Acad. Sci. (U.S.), 55 (1966) 494.

9 B.C. Mayne, Photochem. Photobiol., 8 (1968) 107.

10 J. Barber and G.P.B. Kraan, Biochim. Biophys. Acta, 197 (1970) 49.

11 C.A. Wraight and A.R. Crofts, Eur. J. Biochem., 19 (1971) 386.

12 J.S. Brown, Biochim. Biophys. Acta, 143 (1967) 391.

13 J.C. Goedheer, Biochim. Biophys. Acta, 314 (1973) 191.

14 J.C. Goedheer, Photosynthetica, 4 (1970) 97.

15 G.P.B. Kraan, Thesis, University of Leiden, 1971.

16 W.S. Cohen and W. Bertsch, Biochim. Biophys. Acta, 347 (1974) 371. 